\title{
Alelopatia de espécies da Caatinga
}

\author{
Allelopathy of Caatinga species \\ Alelopatía de la especie Caatinga
}

\section{Resumo}

Para que a implementação de sistemas agroflorestais na Caatinga e de projetos de recuperação de áreas degradadas sejam práticas exitosas, devem ser considerados os efeitos alelopáticos que estarão envolvidos no sistema, pois os mesmos determinam a composição florística e a predominância das espécies vegetais. Esta revisão narrativa de caráter qualitativo foi realizada para obter melhor conhecimento sobre a alelopatia das espécies da Caatinga. Considerou-se: (a) Fatores que influenciam o efeito alelopático: constituintes químicos; $\mathrm{pH}$ e potencial osmótico; solvente de extração; órgão vegetal; preparação física das partes vegetais; temperatura de extração do extrato; sinergismo; concentração do extrato; avaliação do efeito alelopático; (b) Fatores que influenciam na quantidade e qualidade de metabólitos secundários: domesticação da espécie vegetal; características físicas e fisiológicas das sementes da espécie alvo; época do ano; horário de coleta; estresse e local de coleta; interações entre a planta e os microrganismos presentes no solo; substâncias alelopáticas (Inibição ou estímulo?). Entre as possibilidades de investigações destaca-se o desenvolvimento de estudos de processos alelopáticos com espécies arbóreas nativas com o objetivo de determinar quais são as espécies sinérgicas entre si, com capacidade de favorecerem o sucesso na recuperação de áreas degradadas e no manejo sustentável. Averiguar de quais maneiras as condições de estresses (hídrico, salino, térmico, luminoso e nutricional) afetam a quantidade e a qualidade dos metabólitos secundários. Pesquisas podem simular o efeito da serapilheira das diferentes espécies da Caatinga sobre a germinação e desenvolvimento de outras espécies a serem usadas em programas de reflorestamento e em sistemas agrosilvipastoris.

Palavras-chave: Efeitos alelopáticos; Germinação; Metabólitos secundários.

\begin{abstract}
For the implementation of agroforestry systems in the Caatinga and projects for the recovery of degraded areas to be successful practices, the allelopathic effects that will be involved in the system must be considered, as they determine the floristic composition and the predominance of plant species. This qualitative narrative review was carried out to obtain better knowledge about the allelopathy of the Caatinga species. It was considered: (a) Factors that influence the allelopathic effect: chemical constituents; $\mathrm{pH}$ and osmotic potential; extraction solvent; vegetable organ; physical preparation of plant parts; extract extraction temperature; synergism; extract concentration; evaluation of the allelopathic effect; (b) Factors that influence the quantity and quality of secondary metabolites: domestication of the plant species; physical and physiological characteristics of the seeds of the target species; time of the year; collection time; stress and collection site; interactions between the plant and the microorganisms present in the soil; allelopathic substances (inhibition or stimulus?). Among the possibilities of investigations, the development of studies of allelopathic processes with native tree species stands out with the objective of determining which species are synergistic with each other, with the capacity to favor the success in the recovery of degraded areas and in sustainable
\end{abstract}


management. Find out in what ways the stress conditions (water, salt, thermal, light and nutritional) affect the quantity and quality of secondary metabolites. Research can simulate the effect of the litter of different species of the Caatinga on the germination and development of other species to be used in reforestation programs and in agrosilvipastoral systems.

Keywords: Allelopathic effects; Germination; Secondary metabolites.

\section{Resumen}

Para que la implementación de sistemas agroforestales en la Caatinga y proyectos de recuperación de áreas degradadas sean prácticas exitosas, se deben considerar los efectos alelopáticos que estarán involucrados en el sistema, ya que determinan la composición florística y el predominio de especies vegetales. Esta revisión narrativa cualitativa se realizó para obtener un mejor conocimiento sobre la alelopatía de la especie Caatinga. Se consideró: (a) Factores que influyen en el efecto alelopático: componentes químicos; pH y potencial osmótico; disolvente de extracción; órgano vegetal; preparación física de partes de plantas; temperatura de extracción del extracto; sinergismo; concentración de extracto; evaluación del efecto alelopático; (b) Factores que influyen en la cantidad y calidad de metabolitos secundarios: domesticación de las especies vegetales; características físicas y físiológicas de las semillas de la especie objetivo; época del año; tiempo de recolección; estrés y sitio de recolección; interacciones entre la planta y los microorganismos presentes en el suelo; sustancias alelopáticas (inhibición o estímulo?). Entre las posibilidades de investigación, destaca el desarrollo de estudios de procesos alelopáticos con especies arbóreas nativas con el objetivo de determinar qué especies son sinérgicas entre sí, con capacidad para favorecer el éxito en la recuperación de áreas degradadas y en el manejo sustentable. Descubra de qué manera las condiciones de estrés (agua, sal, térmico, lumínico y nutricional) afectan la cantidad y calidad de los metabolitos secundarios. La investigación puede simular el efecto de la hojarasca de diferentes especies de la Caatinga sobre la germinación y desarrollo de otras especies para ser utilizadas en programas de reforestación y en sistemas agrosilvipastorales.

Palabras clave: Efectos alelopáticos; Germinación; Metabolitos secundarios.

\section{Introdução}

Uma reflexão sobre os motivos que impulsionam o desenvolvimento de pesquisas para o Semiárido torna-se bastante oportuna, uma vez que os referidos estudos contribuiriam para uma exploração mais sustentável dos recursos genéticos vegetais, nesse ecossistema tão peculiar que é a Caatinga.

Tecnologias que visem o melhor uso e eficiência do solo, conservação do ambiente e sustentabilidade socioeconômica, vem sendo implantadas como novas formas de produção agrícola. Dessa forma, destaca-se a implantação de sistemas agroflorestais (SAFs) que se baseiam na interação das espécies florestais, culturas agrícolas e/ou animais na mesma área de forma simultânea ou sequencial (Assis Júnior et al., 2003). O sucesso que estes sistemas venham alcançar (Rizvi et al., 1992), bem como a implantação de projetos de recuperação de áreas degradadas dependem do conhecimento das várias interações estabelecidas entre as plantas presentes no mesmo ambiente, entre estas interações destaca-se a alelopatia, a qual refere-se a liberação de compostos aleloquímicos (produtos do metabolismo secundário), produzidos por determinadas espécies, que são responsáveis pela inibição ou estimulação da germinação e/ou desenvolvimento de outras plantas, de forma direta ou indireta.

De acordo com Oliveira et al. (2004) para a recuperação de áreas degradadas, espécies que apresentem potencial alelopático podem ser utilizadas. As plantas, principalmente as espécies florestais que ainda não foram domesticadas, liberam compostos alelopáticos como mecanismos de defesa para o estabelecimento e sobrevivência da espécie (Chou, 1986).

A eliminação dos compostos aleloquímicos para o ambiente pode ser por meio da lixiviação, volatilização, exsudação radicular e decomposição de resíduos, entre outros mecanismos possíveis; ainda pode afetar na dinâmica populacional, determinando em sistemas naturais e cultivados, o padrão e a densidade da vegetação (Machado, 2007). Salienta-se, entretanto, que para que a ação alelopática seja eficaz a liberação deve ser contínua, ou seja, os efeitos aleloquímicos devem persistir no ambiente até os próximos cultivos (Tur et al., 2010).

Os compostos químicos (aleloquímicos) podem ser produzidos em todos os tecidos das plantas e diferem entre as espécies (Taiz \& Zeiger, 2004). A atividade alelopática pode ser encontrada em diversas classes de substâncias naturais como 
os fenóis, alcalóides, glicosídeos, flavonóides, terpenóides, cumarinas, taninos, dentre outros (Hoffmann, 2007). As substâncias alelopáticas, denominadas de aleloquímicos, variam de acordo com a espécie e têm ações diversas nas espécies alvo.

$\mathrm{Na}$ literatura encontram-se muitas informações pertinentes a alelopatia envolvendo plantas daninhas, mas de forma incipiente são encontradas pesquisas focando espécies da Caatinga. Por sua vez, este cenário não diz respeito apenas as espécies do Semiárido Nordestino, pois segundo Marashim-Silva e Aquila (2006) há poucos estudos direcionados para as espécies nativas no Brasil, considerando-se a extensão territorial e a diversidade florística.

Dentre as várias espécies que compõe a flora da Caatinga brasileira podem ser mencionadas, Mimosa tenuiflora (Mart.) Benth. (jurema-preta), Ziziphus joazeiro Mart. (juazeiro), Spondias tuberosa Arruda Câm. (umbuzeiro), Schinopsis brasiliensis Engl. (baraúna), Astronium urundeuva (M.Allemão) Engl. (aroeira do sertão), Erythrina velutina Willd. (mulungu), Caesalpinia ferrea Mart. ex Tul. var. ferrea (pau ferro), Amburana cearensis (Allemão) A.C.Sm. (amburana de cheiro) e Croton sonderianus Mull.Arg. (marmeleiro), dentre outras. A presença de compostos considerados como aleloquímicos nesses vegetais pode afetar a germinação e o desenvolvimento inicial das plântulas.

Os aleloquímicos podem atuar de forma direta e indireta, ou seja, eles atuam diretamente quando se ligam às membranas da planta receptora ou penetram nas suas células, proporcionando alterações no seu metabolismo; e de forma indireta causam modificações nas propriedades edáficas, nas condições nutricionais do solo e nas comunidades microbiológicas (Ferreira \& Áquila, 2000). Fatores como temperatura, intensidade luminosa, características físicas e químicas do solo, ação de microrganismos na rizosfera, idade e tipo de órgão da planta, entre outros, influenciam a natureza e a quantidade de substâncias alelopáticas (Reigosa \& Pedrol, 2002). As funções mais afetadas nos vegetais submetidos a substâncias alelopáticas são: respiração, fotossíntese, abertura dos estômatos, síntese de proteína, inibição do transporte de membrana e da atividade enzimática e alteração no material genético (Spiassi et al., 2015).

A fim de se ter maior precisão nos estudos sobre interferência alelopática, a utilização de bioensaios é de primordial importância, pois há o controle de fatores essenciais ao crescimento e o efeito do composto testado é determinado com maior precisão (Alves, 1992). As substâncias aleloquímicas precisam estar em uma concentração mínima no ambiente para interferirem na atividade metabólica dos organismos (Prates et al., 2000). Há especificidade da resposta da espécie vegetal aos metabólitos secundários, afetando o grau de resistência ou tolerância aos mesmos, assim existem aquelas mais sensíveis, as quais são consideradas bioindicadoras ou plantas indicadoras de atividade alelopática. Uma espécie só será indicada como planta teste caso ela germine de forma rápida e uniforme e que quando submetida a baixas concentrações das substâncias alelopáticas apresente uma sensibilidade suficiente para expressar os resultados (Ferreira \& Áquila, 2000).

A presença de fitotoxidade para alguns vegetais de importância econômica como feijão caupi e melão, foi verificada em bioensaios envolvendo extratos de Libidibia ferrea (Alves et al., 2019) e A. cearenses (Oliveira et al., 2020) respectivamente; tais resultados ratificam a importância de que por instalação de sistemas agroflorestais haja um correto dimensionamento populacional das plantas.

Assim para que a implementação de sistemas agroflorestais na Caatinga e de projetos de recuperação de áreas degradadas sejam práticas exitosas, deve-se considerar os efeitos alelopáticos que estarão envolvidos no sistema, pois os mesmos determinam a composição florística e a predominância das espécies vegetais. Estudos direcionados a avaliação do potencial alelopático das espécies florestais no que diz respeito a inibição da germinação de sementes e crescimento inicial de plântulas de espécies agrícolas, tornam-se fundamentais na geração de conhecimentos consistentes. 


\section{Metodologia}

Esta revisão narrativa de caráter qualitativo, foi realizada para obter melhor conhecimento sobre a alelopatia das espécies da Caatinga. Para isto, esta revisão abrangeu artigos científicos nacionais e internacionais, anais de congresso, livros, comunicados técnicos, teses e dissertações, acessados por meio de consulta nas bases de dados: Periódicos da Capes, SciELO e Google Acadêmico (Pereira et al., 2018).

\section{Resultados e Discussão}

\subsection{Fatores que influenciam o efeito alelopático}

\subsubsection{Constituintes químicos}

A ação das substâncias aleloquímicas não é muito específica, pois dependendo de sua concentração e composição química uma mesma substância pode desempenhar várias funções (Richardson \& Williamson, 1988). Dentro desse contexto, Almeida-Bezerra et al. (2020) destacam a necessidade de revisões de literatura que procurem proporcionar uma melhor compreensão dos mecanismos de ação dos aleloquímicos na natureza. Na literatura farmacológica é possível encontrar a identificação de constituintes químicos de algumas das espécies da Caatinga.

O juazeiro (Z. joazeiro) é uma das espécies endêmicas do bioma Caatinga utilizada na medicina popular, com amplo potencial de uso na indústria de fármacos, em função da presença de saponinas em várias partes da planta, sendo que alguns estudos (Maraschin-Silva \& Aquila, 2005, 2006; Gusman et al., 2008) validaram estas substâncias com capacidade de proporcionarem efeito alopático.

A presença de saponinas foi atribuída por Oliveira et al. (2009) como responsável por causar efeito alelopático desfavorável sobre a germinação de alface nas maiores concentrações do extrato da polpa dos frutos de Z. joazeiro. Em condições naturais estas substâncias hidrossolúveis podem ser liberadas, e atuarem na defesa contra herbívoros e patógenos (Rice,1984; Ferreira \& Aqüila 2000). Oliveira et al. (2009) salientam que os efeitos alelopáticos encontrados poderiam explicar a ausência de plântulas próximas as árvores mãe.

A aroeira-do-sertão (A. urundeuva), amplamente encontrada no Cerrado e Caatinga brasileira, apresentou os taninos como constituintes químicos majoritários (Monteiro et al., 2006), verificando-se também a presença de alcalóides (Lima, 2004), substâncias esteróides diversas como chalconas (Mota, 2006) e terpenos (Fortes, 2006).

Em pereiro (Aspidosperma piryfolium Mart.) e angico (Anadenanthera colubrina (Vell) Brenan. var. cebil. (Gris.) Alts.) foram encontrados taninos e alcalóides; sendo que o extrato de angico ainda apresentou resultados positivos para flavonóides (Santos, 2010).

O sabiá (Mimosa caesalpiniaefolia Benth.), oriunda da Região Nordeste do Brasil (Souza, 2012), apresenta potencial para ser utilizado em sistemas agroflorestais, entretanto, estudos alelopáticos devem ser realizados, pois em sua casca foram encontrados alcalóides, terpenos, esteróides e taninos (Callou, et al. 2012).

A presença de substâncias aleloquímicas poderia explicar o retardamento e a inibição da germinação das sementes de ipê-amarelo (Tabebuia alba (Cham.) Sandw.) expostas aos extratos de folhas de sabiá (Piña-Rodrigues \& Lopes, 2001). Por sinal, os referidos autores salientam que em projetos de recuperação de áreas degradadas o emprego do sabiá deve ser feito com parcimônia e com baixa densidade de plantas, para evitar sua dominância. Entretanto, Ferreira et al. (2010) verificaram que a germinação de sementes de feijão fava (Phaseolus lunatus L.) não foi influenciada pelas diferentes concentrações do extrato de folhas jovens de sabiá, sugerindo o seu uso em sistemas agroflorestais.

A jurema-preta (M. tenuiflora), espécie com grande potencial como indivíduo regenerador de terrenos erodidos (Maia, 2012), apresenta como compostos fitoquímicos os alcalóides, terpenos, esteróides e taninos (Bezerra et al., 2011). Inclusive o 
reduzido ataque de pragas e doenças já foi associado à presença de tanino condensado (17,74\%) nas suas cascas (Paes et al., 2006).

Ao utilizarem o extrato aquoso de sementes de M. tenuiflora, Silveira et al. (2011) verificaram efeito alelopático negativo sobre a germinação das sementes e o desenvolvimento de plântulas de alface. Silveira et al. (2012a) salientam que o não estabelecimento de outras plantas próximas à jurema-preta possa ser decorrente do fato da jurema preta ser uma espécie que perde as folhas no período de seca, onde há uma queda constante com posterior substituição, proporcionando assim um acúmulo das folhas próximo à planta-mãe. Assim, a utilização de $M$. tenuiflora poderia prevenir a colonização de áreas degradadas com espécies invasoras não pertencentes ao bioma Caatinga, conforme sugestão de Giotto et al. (2007) com o uso de Eugenia dysenterica para o bioma Cerrado.

A A. cearensis, popularmente conhecida como umburana-de-cheiro ou cumaru, é uma importante espécie florestal nativa da Caatinga com elevada produção de aleloquímicos. Distintos metabólitos secundários do cumaru já foram isolados, mas as cumarinas são os mais abundantes e importantes que podem causar efeitos alelopáticos (Almeida et al., 2010). Lessa et al. (2017) mostraram que o uso de extratos aquosos de folhas frescas e secas de A. cearensis causou efeito alelopático na germinação de sementes de caruru (Amaranthus deflexus).

O mulungu (E. velutina), trata-se de uma espécie que apresenta rápido crescimento, rusticidade, pro-priedades medicinais, além de ser muito resistente à seca. Uma abordagem fitoquímica de plantas do gênero Erythrina revelou a presença de flavonóides, cumarinas e saponinas, sendo fontes também de alcalóides tetracíclicos do tipo eritrina (Cunha et al., 1996; Rabelo et al., 2001; Virtuoso et al., 2005; Corrêa et al., 2008; Sousa et al., 2008).

Independente da temperatura $\left(25\right.$ e $\left.100^{\circ} \mathrm{C}\right)$ de extração, Oliveira et al. (2012a) observaram que os extratos obtidos de sementes de E. velutina, reduziram a porcentagem e velocidade de germinação de sementes de alface e afetaram o desenvolvimento das plântulas. Considerou-se que a elevada toxidade do extrato de sementes de mulungu possa ser atribuída à presença de aleloquímicos (alcalóides, erisopina, erisodina, eritramina e eritracina) nas sementes, já que os mesmos foram identificados na planta (Castro, 2006).

Durante o período chuvoso (fevereiro-abril) observa-se que as vagens de mulungu ao caírem no solo ficam sob a copa da planta-mãe (Lorenzi, 2002); esta situação pode contribuir para que os aleloquímicos, presentes nas sementes, ao serem liberados no ambiente acabem por limitar o crescimento e o estabelecimento de outras espécies, refletindo no manejo de plantas daninhas, na sucessão ecológica e no estabelecimento de sistemas agroflorestais (Oliveira et al., 2013).

Em pau-ferro ou jucá (C. ferrea), espécie de ampla ocorrência na Caatinga arbórea e arbustiva do Nordeste brasileiro, já foram reconhecidas substâncias com atividade alelopática (Rice, 1984), tais como flavonóides, saponinas, taninos, cumarinas, esteróides e compostos fenólicos, por meio de análise fitoquímica preliminar do extrato hidroalcóolico da casca e das folhas (Lorenzi \& Matos, 2008). Ao utilizarem diferentes proporções de folhas secas em processo de decomposição da espécie . ferrea, Alves et al. (2017) verificaram efeitos alelopáticos sobre a germinação de sementes de feijão de corda, cv. Canapu.

O marmeleiro (C. sonderianus) é considerada a principal espécie colonizadora das Caatingas sucessionais do Nordeste do Brasil (Carvalho et al., 2001). O aroma característico de suas folhas e casca (Lorenzi \& Matos, 2002) é decorrente da presença de um óleo essencial de composição complexa, o qual consta na sua constituição pineno, cânfora, guaiazuleno, e outros monoterpenos, diterpenos e seiquisterpenos. Os mesmos autores atribuem também à presença da substância hidroxicumarina, encontrada nesta espécie, juntamente com o tanino a resposta inibitória do marmeleiro. Aliás, foi atribuído aos monoterpenos, presentes no marmeleiro, os efeitos fitotóxicos nas sementes e vigor em plantas de alface (Alves et al., 2004).

Ao avaliarem o efeito alelopático de extratos de ramos de jurema-preta (M. tenuiflora) e marmeleiro (C. sonderianus) 
sobre a germinação e vigor de feijão macaçar, Brito e Santos (2012) verificaram que o feijão macaçar mostrou-se sensível aos referidos extratos aquosos da parte aérea. Pelo fato das referidas espécies serem fontes de aleloquímicos, os autores sugerem cautela com o uso das mesmas em sistemas agroflorestais.

\subsection{2 pH e Potencial osmótico}

$\mathrm{O}$ efeito alelopático pode ser mascarado quando valores extremos de $\mathrm{pH}$ e potencial osmótico dos extratos atuam sobre as sementes e/ou plântulas; assim quando se desconhece a constituição em açúcares, aminoácidos, ácidos orgânicos, íons e outras moléculas, a avaliação do pH e do potencial osmótico dos extratos vegetais torna-se fundamental (Ferreira \& Áquila, 2000).

Poucos são os trabalhos que averiguam o pH e o potencial osmótico dos extratos utilizados, mostrando assim a necessidade de desenvolvimento de procedimentos padrões a serem empregados nos estudos sobre alelopatia em espécies florestais da Caatinga.

\subsubsection{Solvente de extração}

Observa-se que os resultados nos ensaios com extratos podem apresentar resposta diferenciada em função do solvente utilizado. Em estudos sobre os efeitos alelopáticos de extratos aquosos e metanólicos de sementes de A. cearensis, sobre a germinação de sementes de rabanete e alface, Felix et al. (2010) verificaram que os extratos aquosos foram mais eficientes na inibição da germinação sobre as sementes testes, alface e rabanete, enquanto os extratos metanólicos foram tóxicos apenas às sementes de alface.

O extrato etanólico de cascas de E. velutina em ensaio alelopático foi capaz de influenciar a germinação e crescimento das plantas de alface (Centenaro et al., 2009). Nos estudos com E. velutina constatou-se que a germinação das sementes de alface não foi inibida quando se utilizou o extrato bruto das cascas; no entanto, a fração hidroalcoólica remanescente alterou a morfologia das plântulas causando enovelamento, ausência de pêlos radiculares e de folíolos (Virtuoso, 2005).

Para Inderjit (1996) a extração das partes vegetais não deve ser realizada com solventes orgânicos (clorofórmio, éter, álcool, etc.), já que na natureza isto não ocorre e assim não teria por que liberar compostos que na prática não exerceriam efeito alelopático em condições naturais.

\subsection{4 Órgão vegetal}

As espécies apresentam diferentes atividades alelopáticas em seus órgãos, em função dos aleloquímicos estarem presentes em todos os tecidos das plantas, incluindo folhas, flores, frutos, raízes, rizomas, caules e sementes, entretanto a quantidade e o caminho pelos quais são liberados diferem de espécie para espécie (Putnan \& Tang, 1986).

Foi observado por Silva et al. (2006) que os extratos da casca de A. cearensis afetaram mais a porcentagem de germinação das sementes de sorgo (Sorghum bicolor L.) do que os extratos de folhas, entretanto, o retardamento da germinação ocorreu em ambos os extratos.

As maiores concentrações do extrato $(100 \%, 75 \%$ e $50 \%)$ da polpa dos frutos Z. joazeiro apresentaram efeito alelopático acentuadamente desfavorável sobre a germinação de alface, enquanto o extrato das cascas dos frutos nas concentrações de 75\% e 100\% reduziram a germinação da alface de maneira menos drástica (Oliveira et al., 2009).

Ao avaliarem o efeito alelopático dos extratos aquosos de sementes, flores e cascas de E. velutina na germinação e desenvolvimento de plântulas de alface, Oliveira et al. (2012a) consideraram a existência de potencial alelopático dos extratos feitos com sementes de mulungu sobre as sementes de alface, ao observaram que os extratos obtidos de sementes, independente da temperatura $\left(100^{\circ} \mathrm{C}\right.$ e $\left.25^{\circ} \mathrm{C}\right)$ de extração, reduziram a porcentagem e velocidade de germinação das sementes 
e afetaram o desenvolvimento das plântulas. Os extratos de flores e cascas apesar de não terem afetado a germinação, causaram o aparecimento de plântulas anormais e mortas. Mesmos resultados para o extrato de sementes de mulungu foram obtidos por Oliveira et al. (2013).

Os extratos de folhas, cascas e vagens maduras C. ferrea ao inibirem o desenvolvimento de plântulas de alface demonstraram sua atividade alelopática; sendo que nas maiores concentrações causaram alta porcentagem de plântulas anormais com atrofiamento da raiz, queima e escurecimento da raiz primária, encurvamento do caulículo, geotropismo negativo e menor crescimento das plântulas (Oliveira et al., 2012b).

Ao avaliarem o potencial alelopático dos extratos aquosos de folhas e frutos de Pityrocarpa moniliformis, Pacheco et al. (2017) verificaram que embora os extratos aquosos não tenham afetado a germinação de sementes de M. caesalpiniifolia, houve efeito alelopático negativo sobre a velocidade e o crescimento inicial das plântulas. Pesquisando o potencial alelopático do extrato da polpa do fruto de Pilosocereus gounellei na germinação de sementes de alface e P. gounellei, Santos et al. (2019) observaram que o extrato da polpa do fruto de $P$. gounellei contém aleloquímicos que retardam ou inibem a germinação de sementes, não apenas de alface, mas também de sementes de sua própria espécie (autoalelopatia).

\subsubsection{Preparação física das partes vegetais}

Quanto as partes vegetais que serão utilizadas nos extratos ou na mistura do substrato, as seguintes questões devem ser consideradas: decisão quanto à utilização do material fresco ou desidratado, cortado, moído ou triturado; caso opte pela desidratação preliminar é preciso estabelecer se a secagem será natural ou artificial, no caso desta última a questão recai sobre a temperatura empregada e o tempo de exposição.

Ao avaliarem o potencial alelopático do sabiá ( $M$. caesalpiniaefolia), sobre a germinação de sementes de ipê-amarelo (T. alba), Pinã Rodrigues e Lopes (2001) semearam em substratos umedecidos com extratos aquosos de folhas verdes e secas em diferentes concentrações (1:8, 1:16 e 1:32), e verificaram efeito da diluição e do tipo de folha empregado, com toxidez ou possível efeito alelopático das folhas verdes, independente da dose.

O material com suspeita de alelopatia segundo Inderjit e Dakshini (1995), não deve ser macerado para não liberar substâncias que normalmente não estariam agindo como aleloquímicas em condições naturais, já que as partes vegetativas ao caírem no solo sofrem uma desidratação progressiva.

\subsubsection{Temperatura de extração do extrato}

Uma questão pertinente ao preparo do extrato é com relação à temperatura a ser empregada. Independentemente da temperatura de extração, os extratos aquosos de folhas de aroeira (Schinus terebinthifolius) reduziram a germinação de alface (Souza et al., 2010), por sua vez os extratos de folhas de cagaita (Eugenia dysenterica) obtidos a temperatura ambiente $\left(25^{\circ} \mathrm{C}\right.$ ) proporcionaram maior redução da germinação de alface do que os extratos a quente $\left(60{ }^{\circ} \mathrm{C}\right)$ (Giotto et al., 2007). $\mathrm{O}$ extrato aquoso de sementes de jurema preta obtido a $100{ }^{\circ} \mathrm{C}$ na concentração de $100 \%$ reduziu drasticamente a germinação de alface, sendo que foi verificada anormalidade em todas as plântulas de alface com o uso de extratos a 75 e $100 \%$, obtidos à temperatura ambiente e a $100{ }^{\circ} \mathrm{C}$ (Silveira et al., 2011).

Apesar da extração à quente dos constituintes químicos não ocorrer em condições naturais, Oliveira et al. (2012b) salientam que ocorre uma maior disponibilidade dos aleloquímicos na solução quando a extração ocorre a uma temperatura elevada. Tanto C. ferrea (Frasson et al., 2003) como M. tenuifolia (Paes et al., 2006) possuem elevado teor de taninos, os quais possuem uma maior solubilização em água quente (Trugillo et al., 2003). Além de taninos, Bezerra et al. (2011) destacaram a presença de outros compostos fenólicos e também de saponinas em extratos das cascas de M. tenuifolia, os quais também são mais solúveis em água quente. 
Não foi observada atividade alelopática de M. tenuiflora sobre a germinação de sementes de alface, mas os extratos aquosos de cascas (Silveira et al., 2012a) e folhas (Silveira et al., 2012b) obtidos a quente $\left(100{ }^{\circ} \mathrm{C}\right.$ ) causaram maior porcentagem de plântulas anormais. Entretanto, ambos os extratos (extração à temperatura ambiente e à $100{ }^{\circ} \mathrm{C}$ ) nas maiores concentrações afetaram de forma intensa o comprimento da raiz e da parte aérea, demonstrando assim efeito fitotóxico sobre o desenvolvimento de plântulas de alface.

A elevada quantidade de taninos em sementes de E. velutina (Rêgo Júnior et al.,2011), possivelmente possa ser responsável pelas anormalidades verificadas nas plântulas, independente da temperatura de extração dos extratos.

\subsubsection{Sinergismo}

Quando se utiliza a interação de dois extratos vegetais distintos, em que ambos possivelmente possuem caráter alelopático, há de se considerar que em comunidades de plantas as inibições alelopáticas são o resultado não de um único agente químico, mas da ação de diferentes aleloquímicos (An et al., 1993). Deste modo, pressupõe-se que a atividade biológica de uma mistura de aleloquímicos será determinada não só apenas por sua concentração, mas também por sua interação.

A presença de sinergismo entre compostos isolados já foi registrada por alguns pesquisadores (Kubo et al., 1992; Weidenhamer et al., 1994; Souza Filho, 2006). Brito e Santos (2012) observaram que os maiores prejuízos ao sistema radicular em plântulas de Vigna unguiculata L., foram verificados quando as mesmas ficaram expostas às concentrações do extrato de jurema-preta (M. tenuiflora) juntamente com marmeleiro (C. sonderianus).

\subsubsection{Concentração do extrato}

É consenso de que a concentração e o limite de resposta da espécie afetada a essa concentração determinam a atividade alelopática (Reigosa et a., 1999). Nem sempre a maior concentração do extrato é a que possui maior efeito alelopático, pois ao disponibilizar uma maior quantidade de matéria orgânica rica em $\mathrm{N}$, essencial para o crescimento das culturas, pode ocorrer um acréscimo em algumas variáveis analisadas (Prates et al., 2000). Mas de maneira geral, observa-se o efeito deletério do uso de uma maior concentração do extrato, conforme verificado por Oliveira et al. (2009) e Coelho et al. (2011) ao utilizarem extratos da polpa dos frutos e das sementes de Z. joazeiro, respectivamente, sobre a germinação de alface.

A germinação de sementes de feijão fava ( $P$. lunatus L.) não foi prejudicada pelo uso de diferentes concentrações do extrato de folhas jovens de M. caesalpiniaefolia (Ferreira et al., 2010). Por sua vez, Silveira et al. (2012a) verificaram que o extrato aquoso de cascas de M. tenuifolia nas concentrações de 50, 75 e 100\% reduziram drasticamente o comprimento da raiz e da parte aérea. Silveira et al. (2012b) observaram que o extrato aquoso de folhas de M. tenuifolia extraído a $25^{\circ} \mathrm{C}$ não afetou a germinação, por sua vez o extraído a $100{ }^{\circ} \mathrm{C}$ reduziu a germinação nas maiores concentrações. Por sua vez, o desenvolvimento de plântulas de alface foi prejudicado pelos extratos nas maiores concentrações.

O desenvolvimento de plântulas de alface foi afetado pelas baixas concentrações dos extratos de semente de $A$. cearensis, enquanto a germinação (protrusão da raiz primária) ocorreu normalmente, e segundo Felix et al. (2007) a anormalidade do sistema radicular incapacitou as plântulas para um desenvolvimento futuro.

\subsubsection{Avaliação do efeito Alelopático}

Os efeitos alelopáticos dos compostos provenientes das plantas cultivadas, medicinais e florestais podem ser verificados por meio da submissão das sementes e plântulas a extratos aquosos e/ou alcoólicos de diferentes partes da planta e também a substratos formados pelas respectivas partes vegetais, simulando os efeitos da serapilheira.

O desenvolvimento das plântulas frente a um possível efeito alelopático costuma ser muito mais danoso do que a germinação do ponto de vista fisiológico (protrusão da raiz primária). Ferreira e Aquila (2000) consideram que a anormalidade 
das plântulas, tais como o aparecimento de raízes necróticas, seja mais proeminente do que problemas na germinação das sementes, por ocasião da exposição a substâncias alelopáticas. Pedrol et al. (2006) salientam que os aleloquímicos ao favorecerem a ocorrência de modificações fisiológicas e metabólicas acabam interferindo negativamente no processo germinativo e no desenvolvimento de plântulas. Souza Filho et al. (1997) e Pires e Oliveira (2001) ressaltam que para o estudo de extratos com potencial alelopático, a interferência no desenvolvimento da raiz primária seja um dos aspectos mais cruciais. A explicação para esta sensibilidade às substâncias aleloquímicas pode estar no fato de que as raízes estão em contato mais contínuo com os extratos do que qualquer outra parte da planta (Chung et al., 2001).

Mesmo em baixas concentrações dos extratos aquosos e metanólicos de sementes de A. cearenses, as plântulas de alface e rabanete apresentaram anormalidades, principalmente quanto ao sistema radicular, entretanto a germinação (protrusão da raiz primária) ocorreu normalmente (Félix et al., 2007). As fitotoxinas presentes nos extratos ao causarem alterações morfológicas e anatômicas, proporcionam endurecimento e escurecimento dos ápices radiculares (Cruz-Ortega et al., 1998).

Mesmo que a porcentagem final de germinação não seja significativamente afetada pelas substâncias aleloquímicas, Santana et al. (2006) consideraram a ocorrência de uma modificação no padrão de germinação ao constatarem que as sementes expostas a tais substâncias apresentavam diferenças na velocidade e na sincronia da germinação. A mesma linha de pensamento foi compartilhada por Ferreira e Borghetti (2004), ao afirmarem que frequentemente o efeito alelopático se dá sobre a velocidade de germinação ou sobre outro parâmetro do processo.

É interessante verificar que do ponto de vista ecológico, a interferência negativa dos aleloquímicos no desenvolvimento da plântula é uma estratégia de seleção muito mais eficiente do que evitar a germinação do competidor, pois ao causar a morte dos indivíduos competidores ou mesmo retardando a sua germinação ou o seu crescimento, os membros da espécie beneficiada poderão estabelecer-se de forma mais satisfatória ao driblarem uma competição acirrada por recursos do meio ambiente (Jacobi \& Ferreira, 1991).

\subsection{Fatores que influenciam na quantidade e qualidade de metabólitos secundários}

\subsubsection{Domesticação da espécie vegetal}

As plantas, principalmente as espécies florestais que ainda não foram domesticadas, liberam compostos alelopáticos como mecanismos de defesa para o estabelecimento e sobrevivência da espécie (Chou, 1986). Como grande parte das espécies lenhosas são perenes, elas apresentam mais metabólitos secundários por estarem a mais tempo submetidas a intempéries ambientais, estabelecendo uma relação prolongada com os microrganismos do solo e os possíveis aleloquímicos (Ferreira \& Áquila, 2000).

\subsubsection{Características físicas e fisiológicas das sementes da espécie alvo}

Com relação ao tamanho das sementes das espécies alvo, Souza Filho et al. (2003) salientam que as sementes pequenas são mais sensíveis aos compostos alelopáticos do que as sementes grandes, o que pode estar associado ao fato das sementes pequenas absorverem água mais rapidamente. Dentro deste mesmo contexto, as sementes danificadas, atacadas por insetos ou microrganismos, imaturas, com tegumento mais permeável e de baixo vigor seriam mais afetadas pelo aleloquímicos, por estarem com o seu sistema de membranas desestruturado.

\subsection{3 Época do ano}

Em função da época do ano em que as folhas de Mimosa bimucronata (DC) OK. foram coletadas e da espécie alvo, observou-se que os extratos aquosos das folhas inibiram a germinação de algumas espécies de hortícolas (Jacobi \& Ferreira, 1991). Torquato et al. (2020) verificaram inibição do desenvolvimento de plântulas de alface e Cenchrus echinatus L., por 
ocasião do uso de extrato aquoso de folhas de Senna cearensis Afr. Fern., as quais foram coletadas durante os períodos seco e chuvoso.

\subsubsection{Horário de coleta}

Como o metabolismo primário, com formação de cadeias carbonadas, varia nas diferentes horas do dia, o mesmo pode ser esperado para o metabolismo secundário (Ferreira \& Áquila, 2000). Portanto, o horário de coleta deve ser informado para uma melhor interpretação dos possíveis efeitos alelopáticos e, se possível avaliar a eficiência fotossintética e o potencial hídrico.

\subsubsection{Estresse e local de coleta}

De acordo com Ferreira e Áquila (2000) a quantidade e a qualidade de aleloquímicos de uma espécie, podem variar de um local para outro, pois cada região possui suas especificidades edafoclimáticas e pode estar submetida a eventuais adversidades, as quais podem alterar as vias metabólicas das plantas.

Condições edafoclimáticas (deficiências hídrica e nutricional, temperaturas e intensidade luminosa elevadas, salinidade) estressantes no bioma Caatinga favorecem à produção de metabólitos secundários, principalmente pelas espécies não domesticadas (Lima, 1989), como um mecanismo de defesa para a sobrevivência e estabelecimento da espécie (Chou, 1986). Para o bioma Cerrado considerações semelhantes foram feitas por Oliveira (2003) ao considerar a vegetação continuamente submetida aos estresses metabólicos, os quais agravam a competição ao interferirem no estabelecimento das espécies vegetais.

Enfatizando que uma das principais consequências dos aleloquímicos no desenvolvimento da plântula seja a necrose na raiz primária (Ferreira \& Áquila, 2000), é de se esperar que as espécies com potencial alelopático que estejam sendo utilizadas em sistemas agroflorestais ou em áreas de recuperação de áreas degradadas, restrinjam o desenvolvimento de outras espécies e consequentemente o seu estabelecimento. Sendo que esta interferência tende a ser mais intensa no bioma Caatinga, por características inerentes ao próprio bioma tais como a irregularidade e a má distribuição da precipitação e o alto índice de evaporação.

Os solos arenosos, por terem menor adsorção que nos solos coloidais, contribuem para que os aleloquímicos liberados sejam mais efetivos, pois os mesmos ficam livres, na fase aquosa do solo (Inderjit \& Dakshini, 1995).

\subsubsection{Interações entre a planta e os microrganismos presentes no solo}

A ação de microrganismos ao reduzir ou aumentar a atividade biológica de um aleloquímico, pode interferir na resposta alelopática em campo (Mano, 2006).

Mesmo após a morte das plantas, as substâncias alelopáticas ainda permanecem nos tecidos vegetais até serem liberadas por volatilização ou por lixiviação, sendo que após serem depositadas no solo e atingirem uma concentração necessária, passam a influenciar não só no desenvolvimento das plantas como também no desenvolvimento dos microrganismos (Almeida et al., 1991). Os microrganismos do solo por sua vez, podem aumentar ou diminuir o tempo de residência, a persistência e a transformação dos aleloquímicos, além de inativá-los (Ferreira \& Áquila, 2000).

A M. tenuiflora é considerada uma espécie ideal para ocupar áreas severamente degradadas e com reduzida disponibilidade de nitrogênio e fósforo, por ter uma elevada capacidade de associar-se com bactérias do gênero Rhizobium e fungos micorrízicos (Almeida et al., 1991; Mergulhão et al., 2007). 


\subsubsection{Substâncias alelopáticas: inibição ou estímulo?}

De maneira geral, as substâncias alelopáticas ao interferirem na divisão celular, na permeabilidade de membranas, na ativação de enzimas e na produção de hormônios nas plantas, acabam inibindo ou retardando o processo germinativo das sementes e o desenvolvimento/crescimento das plantas (Rodrigues et al., 1992). Dentro desse contexto, Silva et al. (2020) verificaram efeito inibitório de extratos aquosos das folhas de Capparis hastata e Piptadenia moniliformis, sobre o processo de germinação e estabelecimento inicial de $M$. hostilis. O mesmo foi observado por Torquato et al. (2020) por ocasião da submissão de diásporos de alface e C. echinatus L., aos extratos aquosos de S. cearensis. Araújo et al. (2021) também constataram fitotoxidez à germinação das sementes e emergência das plântulas de M. caesalpiniifolia, por ocasião do emprego de extratos foliares de Cenostigma bracteosum, a partir da concentração de 5\%.

Por sua vez, o extrato de folhas de $C$. sonderianus proporcionou efeito positivo no comprimento da raiz das plântulas de alface (Maia et al., 2013). Alves et al. (2020) observaram que o extrato de folhas frescas de M. tenuiflora, nas concentrações de $25 \%$, 50\% e $75 \%$ e $100 \%$, favoreceu o processo germinativo das sementes de Bidens pilosa. Araújo et al. (2021) verificaram que os extratos foliares de Sarcomphalus joazeiro contribuíram para uma melhor germinação e vigor das plântulas de M. caesalpiniifolia. De acordo com Gatti et al. (2004), todos ou a maioria dos compostos orgânicos que causam efeitos deletérios em uma dada concentração, atuariam de forma estimulante quando presentes em concentrações menores.

\section{Considerações Finais}

1. Os poucos trabalhos encontrados com espécies da caatinga são mais restritos a averiguação do potencial alelopático sobre a germinação e desenvolvimento inicial de plântulas de algumas espécies hortícolas e produtoras de grãos. Dentro deste cenário, torna-se proeminente o desenvolvimento de estudos de processos alelopáticos com espécies arbóreas nativas (florestais e/ou frutíferas) com o objetivo de determinar quais são as espécies sinérgicas entre si, com capacidade de favorecerem o sucesso na recuperação de áreas degradadas e no manejo sustentável.

2. Para compor os sistemas agroflorestais e silvipastoris, verificar propriedades alelopáticas em espécies que apresentem este potencial.

3. Desenvolver estudos sobre possíveis associações, entre espécies da Caatinga e fungos micorrízicos e bactérias fixadoras de nitrogênio, uma vez que um aporte de fósforo e nitrogênio proporcionaria um "saldo energético" no metabolismo de tais espécies, nas condições estressantes do semi árido.

4. Averiguar de quais maneiras as condições de estresses (hídrico, salino, térmico, luminoso e nutricional) afetam a quantidade e qualidade dos metabólitos secundários.

5. Pesquisas podem ser direcionadas para a colheita de diversos órgãos da planta em diferentes épocas do ano e períodos de coleta (manhã, tarde, noite e madrugada) para observar possíveis influências sobre a quantidade e qualidade de metabólitos secundários; ressalva-se que no caso de folhas deve-se averiguar o potencial hídrico por ocasião da coleta.

6. Realizar estudos comparativos entre a germinação fisiológica (protrusão da raiz primária) e a germinação do ponto de vista agronômico (porcentagem de plântulas normais), quanto a submissão das sementes a extratos vegetais de diferentes órgãos da planta e também com relação à semeadura das mesmas em substratos confeccionados com os respectivos órgãos.

7. Procurar simular o efeito da serapilheira (substratos com misturas de areia e órgãos vegetais em diferentes proporções e em diferentes períodos de incorporação) das diferentes espécies da Caatinga sobre a germinação e desenvolvimento de outras espécies da Caatinga a serem usadas em programas de reflorestamento e em sistemas agrosilvipastoris. Observa-se que as plantas pré-existentes em uma dada área, por meio da liberação de aleloquímicos ao meio, tenderão a influenciar a sucessão vegetativa. 
8. Coleta de diferentes órgãos vegetais em diferentes locais, haja vista que as condições edafoclimáticas ao influenciarem o desenvolvimento e crescimento da planta, indubitavelmente afetam a quantidade e qualidade de metabólitos secundários, assim trabalhos que façam esta abordagem deverão registrar tais condições para melhor explicar os resultados obtidos.

9. Realizar estudos sobre os efeitos das secagens natural e artificial na quantidade e qualidade dos metabólitos secundários e, consequentemente no potencial alelopático.

10. Avaliar a interferência alelopática em sementes com diferenças quanto a qualidade fisiológica e física.

\section{Referências}

Almeida, J. R. G. S., Guimarães, A. G., Siqueira, J. S., Santos, M. R. V., Lima, J. T., Nunes, X. P., \& Quintans-Júnior, L. J. (2010) - Amburana cearenses uma revisão química e farmacológica. Scientia Plena, 6:11, 1-8.

Almeida, O. S. (2007). Biologia floral, tendências reprodutivas e efeito alelopático da tulase (Ocimum sanctum L.). Vitória da Conquista: Universidade Estadual do Sudoeste da Bahia, 90p. Dissertação Mestrado.

Almeida, R. T., Vasconcelos, I., \& Freire, V. F. (1991). Efeitos de níveis de fosfato de rocha e da inoculação de Rhizobium sp. e Glomus macrocarpum TUL. sobre o desenvolvimento da jurema preta. Ciências Agronômicas, 22:1/2, 1-5.

Almeida-Bezerra, J. W., Viana, J. W. M., Silva, V. B. da., Costa, A. R., Costa, M. H. N. da., Santos, M. A. F. dos., Macedo, G. F., Lima, E. E., Torquato, I. H. S., Rodrigues, J. L. G., Teixeira, P. H. R., Oliveira, J. P. C. de., Batista, A. P., Sousa, F. V. A. de., Pereira, C. M., \& Correia, D. B. (2020) Alelopatia? Não sei! Nunca Vi! Eu só ouço falar! Research, Society and Development, 9:12, e19391210873. 10.33448/rsd-v9i12.10873

Alves, R. J. R., Silva, M. A. D., Alves, R. M., Dvoskin, D. M., Moura, D. P., \& Silva, L. M. (2020). Allelopathic influence of the aqueous extract of fresh leaflets of Mimosa tenuiflora (Willd.) Poir. on the germination of Bidens pilosa L. Research, Society and Development, 9:9, e752998061. http://dx.doi.org/10.33448/rsd-v9i9.8061

Alves, R. M., Silva, M. A. D., Silva, J. N., Costa, R. S., Santos, B. K. L, Lima, \& E. S. (2019). Efeito alelopático de Libidibia ferrea Mart. sobre o vigor das sementes de feijão-caupi. Revista Verde de Agroecologia e Desenvolvimento Sustentável, 14:3, 476-479.

Alves, M. C. S., Filho, S. M., Innecco, R., \& Torres, S. B. (2004). Alelopatia de extratos voláteis na germinação de sementes a no comprimento da raiz de alface. Pesquisa Agropecuária Brasileira, 39:11, 1083-1086. http://dx.doi.org/10.1590/S0100-204X2004001100005

Alves, P. L. C. A. (1992). Estudo das propriedades alelopáticas de espécies de Eucalyptus spp. e sua potencialidade no manejo de plantas daninhas. Relatório FINEP: FCAV, 273p.

An, M., Hohnson, I. R., \& Lovett, J. V. (1993). Mathematical modeling allelopathy - biological response to allelochemicals and its interpretation. Journal of Chemical Ecology, 19:10, 2379-2388. https://doi.org/10.1007/BF00979671

Araújo, F. dos S., Medeiros, J. A. D. de., Félix, F. C., Correia, L. A. da S., Ferrari, C. dos S., \& Pacheco, M. V. (2021). O lixiviado das folhas de Sarcomphalus joazeiro e Cenostigma bracteosum estimula ou inibe a germinação de Mimosa caesalpiniifolia? Research, Society and Development, 10:3, e15610313073. 10.33448/rsd-v10i3.13073.

Assis Júnior, S. L., Zanuncio, J. C., Kasuya, M. C. M., Couto, L., \& Melidoet, R. C. N. (2003). Atividade microbiana do solo em sistemas agroflorestais, monoculturas, mata natural e área desmatada. Revista Árvore, 27:1, 35-41.

Bezerra, D. A. C., Rodrigues, F. F. G., Costa, J. G. M., Pereira, A. V., Sousa, E. O., \& Rodrigues, O.G. (2011). Abordagem fitoquímica, composição bromatológica e atividade antibacteriana de Mimosa tenuiflora (Wild) Poiret e Piptadenia stipulacea (Benth) Ducke. Acta Scientiarum Biological Sciences, 33:1, 99-106. https://doi.org/10.4025/actascibiolsci.v33i1.5366

Brito, I. C. A., \& Santos, D. R. (2012). Alelopatia de espécies arbóreas da caatinga na germinação e vigor de sementes de feijão macacar. Revista Verde, 7:1, $129-140$.

Callou, M. J. A., Miranda, R. C. M., Feitosa, T. R., Arruda, F. V. F., Nascimento, M. S., \& Gusmão, N. B. (2012). Avaliação da atividade antimicrobiana da casca de Mimosa caesalpiniifolia Benth (sabiá). Scientia Plena. 8:1, 1-7.

Cândido, A. C. S. (2007). Potencial Alelopático da parte aérea de Senna occidentalis (L.) Link (Leguminosae, Caesalpinioideae): bioensaios em laboratório e casa de vegetação. Campo Grande: UFMS, 99p. Dissertação Mestrado.

Carvalho, F. C., Araújo Filho, J. A., Garcia, R., Perei-Ra Filho, J. M., \& Albuquerque, V. M. (2001). Efeito do corte da parte aérea na sobrevivência do marmeleiro (Croton sonderianus Muell.Arg.). Revista Brasileira de Zootecnia, 30, 930-934.

Castro, D. L. L. (2006). Aspectos toxicológicos das plantas medicinais utilizadas no Brasil: um enfoque qualitativo no Distrito Federal. Brasilia: UNB - Centro de Excelência em Turismo. 54p (Monografia),

Centenaro, C., Corrêa, L. G. P., Karas, M. J., Virtuoso, S., Dias, J. E. G., Miguel, O. G., \& Miguel, M. D. (2009). Contribuição ao estudo alelopático de Erythrina velutina Willd., Fabaceae. Revista Brasileira Farmacognosia, 19:1, 304-308. http://dx.doi.org/10.1590/S0102-695X2009000200021 
Chou, C. H., \& Kuo, Y. L. (1986). Allelopathic research of subtropical vegetation in Taiwan. III. Allelopathic exclusion of understory by Leucaena leucocephala (Lam.) de Wit. Journal of Chemical Ecology, 12, 1431-1448.

Coelho, M. F. B., Maia, S. S. S., Oliveira, A. K., \& Diógenes, F. E. P. (2011). Atividade alelopática de extrato de sementes de juazeiro. Horticultura Brasileira, 29:3, 108-111. http://dx.doi.org/10.1590/S0102-05362011000100018

Corrêa, M. F. P., Melo, G. O., \& Costa, S. S. (2008). Substâncias de origem vegetal potencialmente úteis na terapia da asma. Revista Brasileira Farmacognosia, 18, 785-797. http://dx.doi.org/10.1590/S0102-695X2008000500025

Cruz-Ortega, R., Anaya, A. L., Hernández-Bautista, B. E., \& Laguna-Hernández, G. (1998). Effects of allelochemical stress produced by Sicyios deppei on seedling root ultrastructure of Phaseolus vulgaris e Curcubita ficifolia. Journal of Chemical Ecology, 24:12, 2039-2057.

Cunha, E. V. L., Dias, C., Barbosa-Filho, J. M., \& Gray, A. I. (1996). Eryvellutinone, an isoflavone from the stem bark of Erythrina vellutina. Phytochemistry, $43,1371-1373$

Felix, R. A. Z., Ono, E. O., \& Araújo, F. P. (2010). Efeitos alelopáticos de extratos de Amburana cearensis na germinação de sementes de rabanete e alface. Cultivando o Saber, 3:1, 18-31.

Felix, R. A. Z., Ono, E. O., Silva, C. P., Rodrigues, J. D., \& Pieri, C. (2007). Efeitos alelopáticos da Amburana cearensis L. (Fr.All.) AC Smith na germinação de sementes de alface (Lactuca sativa L.) e de rabanete (Raphanus sativus L.). Revista Brasileira de Biociências, 5:2, 138-140.

Ferreira, A. G., \& Borghetti, F. (2004). Germinação: do básico ao aplicado: Ed. Artimed. 323p.

Ferreira, A. G., \& Áquila, M. E. A. (2000). Alelopatia: uma área emergente da ecofisiologia. Revista Brasileira de Fisiologia Vegetal, 12, 175-204.

Ferreira, E. G. B. S., Matos, V. P., Sena, L. H. M., \& Sales, A. G. F. A. (2010). Efeito alelopático do extrato aquoso de sabiá na germinação de sementes de fava. Revista Ciência Agronômica, 41:3, 463-467.

Fortes, J. C., \& Guedes, M. I. F. (2006). Atividade antimicrobiana do óleo essencial de Croton argyrophylloides Muell Arg e de frações isoladas dos extratos

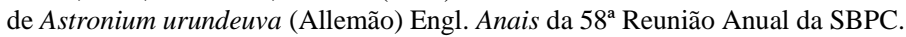

Frasson, A. P. Z., Bittencourt, C. F., \& Heinzmann, B. M. (2003). Caracterização físico-química e biológica do caule de Caesalpinia ferrea Mart. Revista Brasileira de Farmacognosia, 13:1, 35-39. https://doi.org/10.1590/S0102-695X2003000100004

Gatti, A. B., Perez, S. C. J. G. A., \& Lima, M. I. S. (2004). Atividade alelopática de extratos aquosos de Aristolochia esperanzae O. Kuntze na germinação e no crescimento de Lactuca sativa L. e Raphanus sativus L. Acta Botânica Brasílica, 18:3, 459-472. https://doi.org/10.1590/S0102-33062004000300006

Giotto, A. C., Oliveira, S. C. C., \& Silva, J. G. P. (2007). Efeito alelopático de Eugenia dysenterica Mart. ex DC. Berg. (Myrtaceae) na germinação e no crescimento de Lactuca sativa L. (Asteraceae). Revista Brasileira de Biociências, 5:2, 600-602.

Gusman, G. S., Bittencourt, A. H. C., \& Vestena, S. (2008). Alelopatia de Baccharis dracunculifolia DC. sobre a germinação e desenvolvimento de espécies cultivadas. Acta Scientiarum, 30, 119-125.

Hoffmann, C. E. F., das Neves, L. A. S., Bastos, C. F., \& da Luz Wallau, G. (2007). Atividade alelopática de Nerium oleander L. e Dieffenbachia picta Schott em sementes de Lactuca sativa L. e Bidens pilosa L. Revista de Ciências Agroveterinárias, 6:1, 11-21.

Inderjit. (1996). Plant phenolics in allelopathy. The Botanical Review, 62, 186-202. https://doi.org/10.1007/BF02857921

Inderjit, \& Dakshini, K. M. M. (1995). On laboratory biossays in allelopathy. The Botanical Review, 61, 28-44. https://doi.org/10.1007/BF02897150

Jacobi, U. S., \& Ferreira, A. G. 1991. Efeitos alelopáticos de Mimosa bimucronata (DC.) OK. sobre espécies cultivadas. Pesquisa Agropecuária Brasileira, $26,935-943$.

Kubo, I., Muroi, H., \& Himejina, M. (1992). Antimicrobial activity of green tea flavor components and their combination effect. Journal Agricultural Food Chemical, 40:1, 245-248. https://doi.org/10.1021/jf00014a015

Lessa, B. F. T., Silva, M. L. S., Barreto, J. H. B., \& Oliveira, A. B. (2017). Efeitos alelopáticos de extratos aquosos de folhas de Amburana cearensis e Plectranthus barbatus na germinação de Amaranthus deflexus. Revista de Ciências Agrárias, 40:1, 79-86. https://doi.org/10.19084/RCA16063

Lima, D. (1989). Plantas das Caatingas: Academia Brasileira de Ciências. 243 p.

Lima, E. O., Pereira, F. O., Lima, I. O., Trajano, V. N., \& Souza, E. L. (2004). Schinus terebenthifolius Raddi: avaliação do espectro de ação antimicrobiana de seu extrato aquoso. Infarma, 16, 7-8.

Lorenzi, H. (2002). Árvores brasileiras: manual de identificação e cultivo de plantas arbóreas nativas do Brasil. (2a.ed.): Instituto Plantarum. 368p.

Lorenzi, H., \& Matos, F. J. A. (2002). Plantas medicinais no Brasil: nativas e exóticas: Instituto Plantarum de estudos da flora, 207p.

Machado, S. (2007). Allelopathic Potential of various plant species on downy brome: Implications for weed control in wheat production. Agronomy Journal, 99:1, 127-132. https://doi.org/10.2134/agronj2006.0122

Maia, S. S. S., Coelho, M. F. B., Oliveira, A. K., \& Diógenes, E. P. (2013). Atividade biológica de extratos de espécies do Rio Grande do Norte em sementes de alface. Revista Verde, 8:4, 169 - 173

Maia, G. N. (2012). Caatinga: árvores e arbustos e suas utilidades. Fortaleza: Printcolor Gráfica e Editora, 413p 
Mano, A. R. O. (2006). Efeito alelopático do extrato aquoso de sementes de cumaru (Amburana cearensis S.) sobre a germinação de sementes, crescimento e crescimento de plântulas de alface, picão-preto e carrapicho. Fortaleza: UFC, 102p. Dissertação Mestrado.

Maraschin-Silva, F., \& Áquila, M. E. A. (2005). Potencial alelopático de Dodonaea viscosa (L.) Jacq. Iheringia, Série Botanica, 60, 91-98. https://isb.emnuvens.com.br/iheringia/article/view/208

Maraschin-Silva, F., \& Áquila, M. E. A. (2006). Potencial alelopático de espécies nativas na germinação e vigor de Lactuca sativa L. (Asteraceae). Acta Botanica Brasilica, 20:1, 61-69. http://dx.doi.org/10.1590/S0102-33062006000100007

Maraschin-Silva, F., \& Aquila, M. E. A. (2006). Contribuição ao estudo do potencial alelopático de espécies nativas. Revista Árvore, 30, 547-555. http://dx.doi.org/10.1590/S0100-67622006000400007

Mergulhão, A. C. E. S. Oliveira, J. P., Burity, H. A., \& Maia, L. C. (2007). Potencial de infectividade de fungos micorrízicos arbusculares em áreas nativas e impactadas por mineração gesseira no semi árido brasileiro. Hoehnea, 34:3, 341-348. http://dx.doi.org/10.1590/S2236-89062007000300005

Monteiro, J. M., Albuquerque, U. P., Neto, E. M. F. L., Araújo, E. L., Albuquerque M. M., \& Amorim, E. L. C. 2006. The effects of seasonal climate changes in the Caatinga on tannin levels in Myracrodruon urundeuva (Engl.) Fr. All. and Anadenanthera colubrina (Vell.) Brenan. Brazilian Journal of Pharmacognosy, 16:3, 338-344. http://dx.doi.org/10.1590/S0102-695X2006000300010

Mota, C. W. C. (2006). Efeito da chalconas (Myracroduon urundeuva Fr. All.) nas fraturas expostas induzidas em ratos. Dissertação de Mestrado, Curso de Pós Graduação em Cirurgia, Universidade Federal do Ceará.

Oliveira, A. K., Coelho, M. F. B., \& Diogenes, F. E. P. (2020). Atividade alelopática de extratos de sementes de Amburana cearensis na emergência de melão. Revista Caatinga, 33:1, 274-280. http://dx.doi.org/10.1590/1983-21252020v33n130rc

Oliveira, A. K., Coelho, M. F. B., Maia, S. S. S, Diógenes, F. E. P., \& Medeiros Filho, S. (2013). Potencial alelopático do extrato aquoso de sementes de mulungu (Erythrina velutina Willd.). Revista Brasileira de Ciências Agrárias, 8:2, 252-257. 10.5039/agraria.v8i2a1899

Oliveira, A. K., Coelho, M. F. B., Maia, S. S. S., Diógenes, F. E. P., \& Medeiros Filho, S. (2012a). Alelopatia de extratos de diferentes órgãos de mulungu na germinação de alface. Horticultura Brasileira, 30:3, 480-483. http://dx.doi.org/10.1590/S0102-05362012000300020

Oliveira, A. K., Coelho, M. F. B., Diógenes, F. E. P., \& Maia, S. S. S. (2012b). Atividade alelopática de extratos de diferentes orgãos de Caesalpinia ferrea na germinação de alface. Ciência Rural, 42:8, 1397-1403. http://dx.doi.org/10.1590/S0103-84782012000800011

Oliveira, A. K., Diógenes, F. E. P., Coelho, M. F. B., \& Maia, S. S. S. (2009). Alelopatia em extratos de frutos de juazeiro (Ziziphus joazeiro Mart. Rhamnaceae). Acta Botânica Brasílica, 23:4, 1186-1189. http://dx.doi.org/10.1590/S0102-33062009000400029

Oliveira, S. C. C., Ferreira, A. G., \& Borghetti, F. (2004). Efeito alelopático de folhas de Solanum lycocarpum A. St.-Hil. (Solanaceae) na germinação e crescimento de Sesamum indicum L. (Pedaliaceae) sob diferentes temperaturas. Acta Botanica Brasilica, 18:3, 401-406. http://dx.doi.org/10.1590/S010233062004000300001

Oliveira, S. C. C. (2003). Alelopatia em Solanum lycocarpum St. Hil. (Solanaceae). 2003. 78 f. Dissertação (Mestrado em Botânica) - Curso de PósGraduação em Botânica, Universidade de Brasília, Brasília.

Paes, J. B., Diniz, C. E. F., \& Marinho, I. V. (2006). Avaliação do potencial tanífero de seis espécies florestais de ocorrência no semi árido brasileiro. Cerne, $12: 3,232-238$.

Pacheco, M. V., Felix, F. C., Medeiros, J. A. D., Nunes, S. L., Castro, M. L. L., Lopes, A. L.S., \& Souza, W. M. A. T. (2017). Potencial alelopático dos extratos de folhas e frutos de Pityrocarpa moniliformis sobre a germinação de sementes de Mimosa caesalpiniifolia. Agroecossistemas, 9:2, 250-262. doi: http://dx.doi.org/10.18542/ragros.v9i2.5029

Pedrol, N., González, L., \& Reigosa, M. J. (2006). Allelopathy and abiotic stress. In: Reigosa, M. J., Pedrol, N., \& González, L. (Eds). Allelopathy: A physiological process with ecological implications. Springer, Dordrecht, Holanda, p.171-209.

Pereira, A. S., Shitsuka, D. M., Parreira, F. J., \& Shitsuka, R. (2018). Metodologia da Pesquisa Científica. Santa Maria, Brasil: Núcleo de Tecnologia Educacional da Universidade Federal de Santa Maria.

Piña-Rodrigues, F. C. M., \& Lopes, B. M. (2001). Potencial alelopático de Mimosa caesalpinaefolia Benth sobre sementes de Tabebuia alba (Cham.) Sandw. Floresta e Ambiente, 8:1, 130-136.

Piña-Rodrigues, F. C. M., Reis, L. L., \& Marques, S. S. (1997). Sistema de plantio adensado para a revegetação de áreas degradadas da Mata Atlântica: Bases ecológicas e comparações de custo/benefício com o sistema tradicional. Floresta \& Ambiente, 4: 30-41.

Pires, N. M., \& Oliveira, V. R. 2001. Alelopatia. In: Oliveira Junior. R. S., Constantin, J. (coords). Plantas daninhas e seu manejo. Guaíba: Agropecuária. p.145-185.

Prates, H. T., Paes, J. M. V., Pires, N. M., Pereira Filho, I. A., \& Magalhães, P. C. (2000). Efeito do extrato aquoso de leucena na germinação e no crescimento do milho. Pesquisa Agropecuária Brasileira, 35:5, 909-914.

Putnan, A. R., Tang, C. S. (1986). In: Putnan, A. R., \& Tang, C. S. The science of allelopathy: John Wiley \& Sons. p. 1-19.

Rabelo, L. A., Agra, M. F., Cunha, E. V. L., Silva, M. S., \& Barbosa-Filho, J. M. (2001). Homohesperetin and phaseollidin from Erythrina velutina. Biochemical Systematics and Ecology, 29, 543-544. 10.1016/s0305-1978(00)00077-6

Rêgo Júnior, N. O., Fernandez, L. G., Castro, R. D., Silva, L. C., Gualberto, S. A., Pereira, M. L. A., \& Silva, M. V. (2011). Compostos bioativos e atividade antioxidante de extratos brutos de espécies vegetais da Caatinga. Brazilian Journal of Food Technology, 14:1, 50-57. 10.4260/BJFT2011140100007 
Reigosa, M. J., \& Pedrol, N. (2002). Allelopathy: From Molecules to Ecosystems: Science Publishers, 316 p.

Rice, E. L. (1984). Allelopathy. Academic Press Inc.

Richardson, D. R., \& Williamson, G. B. (1998). Allelopathic effects of shrubs of the sand pine scrub on pines and grasses of the sandhills. Forest Science, 34, 592-605. https://doi.org/10.1093/forestscience/34.3.592

Santana, D. G., Ranal, M. A., Mustafa, P. C. Y., \& Silva, R. M. G. (2006). Germination meansurements to evaluate allelopathic interactions. Allelopathy Journal, 17, 43-52.

Santos, A. P., Hassemer, G., \& Meiado, M. V. (2019). Study of the allelopathic potential of the fruit pulp of Pilosocereus gounellei (Cactaceae). Journal of the Torrey Botanical Society 146(3): 174-181, 2019. https://doi.org/10.3159/TORREY-D-18-00019.1

Santos, P. B. (2010). Prospecção fitoquímica e a composição bromatológica das folhas de Aspidosperma pyrifolium Mart. e Anadenanthera colubrina (Vell.) Brenan. Var. cebil. (Gris.) Alts. Patos, PB: UFCG, 45 p. (Dissertação -Mestrado em Zootecnia - Sistemas Agrossilvipastoris no Semi Árido).

Silva, J. N. da., Silva, M. A. D. da., Rocha, A. K. P., Alves, R. M., Silva, E. F. da., Leal, L. de S. G., \& Moura, D. P. de. (2020). Alelopatia de Piptadenia moniliformis e Capparis hastata sobre o vigor de sementes de Mimosa hostilis. Research, Society and Development, 9:8, e472985527. 10.33448/rsdv9i8.5527.

Silva, W. A., Nobre, A. P., Leite, A. P., Silva, M. S. C., Lucas, R. C., \& Rodrigues, O. G. (2006). Efeito alelopático de extrato aquoso de Amburana cearensis A. Smith na germinação e crescimento de sementes de sorgo (Sorghum bicolor L.). Agropecuária Científica no Semiárido, 2:1. http://dx.doi.org/10.30969/acsa.v2i1.22

Silveira, P. F., Maia, S. S. S., \& Coelho, M. F. B. (2011). Atividade alelopática do extrato aquoso sementes de jurema preta na germinação de alface. Revista de Ciências Agrárias, 54:2, 101-106. 10.4322/rca.2012.001

Silveira, P. F., Maia, S. S. S., \& Coelho, M. F. B. (2012a). Atividade alelopática do extrato aquoso de cascas de jurema preta na germinação de alface. Revista Caatinga, 25:1, 20-27.

Silveira, P. F. S., Coelho, M. F. B., \& Maia, S. S. S. (2012b). Potencial alelopático do extrato de folhas de Mimosa tenuiflora (Willd.) Poir. na germinação de Lactuca sativa L. Bioscience Journal, 28:3, 472-477.

Souza, C. S. M. (2012). Diretrizes para conservação da espécie Mimosa caesalpiniiolia Benth., Macaíba-RN (Dissertação de Mestrado). Universidade Federal do Rio Grande do Norte, Natal, Rio Grande do Norte.

Sousa, F. C. F., Melo, C. T. V., Citó, C. O. M., Félix, F. H. C., Silvânia, M. M.; Vasconcelos, S. M. M., Fonteles, M. M. F.; Barbosa Filho, J. M., \& Viana, G. S. B. (2008). Plantas medicinais e seus constituintes bioativos: uma revisão da bioatividade e potenciais benefícios nos distúrbios da ansiedade em modelos animais. Revista Brasileira de Farmacognosia, 18:4, 642-654. https://doi.org/10.1590/S0102-695X2008000400023

Souza, F. M., Gandolfi, S., Perez, S. C. J. G. A., \& Rodrigues, R. R. (2010). Allelopathic potential of bark and leaves of Esenbeckia leiocarpa Engl. (Rutaceae). Acta Botânica Brasílica, 24:1, 169-174. https://doi.org/10.1590/S0102-33062010000100016

Souza Filho, A. P. S. (2006). Proposta metodológica para análise da ocorrência de sinergismo e efeitos potencializadores entre aleloquímicos. Planta Daninha, 24:3, 607-610. https://doi.org/10.1590/S0100-83582006000300025

Souza Filho, A. P. S., Alves, S. M., \& Figueiredo, F. J. C. (2003). Efeitos alelopáticos do calopogônio em função da sua idade e da densidade de sementes da planta receptora. Planta Daninha, 21:2, 211-218.

Spiassi, A., Nóbrega, L. H. P., Rosa, D. M., Pacheco, F. P., Senem, J., \& Lima, J. P. (2015). Allelopathic effects of pathogenic fungi on weed plants of soybean and corn crops. Bioscience Journal, 31:4, 1037-1048. https://doi.org/10.14393/BJ-v31n4a2015-26142

Taiz L., Zeiger E. (2004). Fisiologia vegetal. (3a.ed.): Artmed, 719 p.

Torquato, I. H. S., Costa, N. C. da., Pereira, K. S., Campos, N. B., Oliveira, A. A. de., Generino, M. E. M., Bezerra, J. W. A., Santos, M. A. F. dos., Sousa, J. D., Boligon, A. A., \& Silva, M. A. P. da. (2020) Composição Polifenólica e Potencial Alelopático de Senna cearensis Afr. Fern. (Fabaceae). Research, Society and Development, 9: 8, e577986207. 10.33448/rsd-v9i8.6207.

Trugilho, P. F., Mori, F. A., Lima, J. T., \& Cardoso, D. P. (2003). Determinação do teor de taninos na casca de Eucalyptus spp. Cerne, 9:2, $246-254$.

Tur, C. M., Borella, J., \& Pastorini, L. H. (2010). Alelopatia de extratos aquosos de Duranta repens sobre a germinação e o crescimento inicial de Lactuca sativa e Lycopersicum esculentum. Revista Biotemas, 23:2, 13-22. https://doi.org/10.5007/2175-7925.2010v23n2p13

Venzon, M., Paula Júnior, T. J., \& Pallini, A. (2005). Controle alternativo de pragas e doenças: EPAMIG, 359 p.

Virtuoso, S. (2005). Estudo fitoquímico e biológico das cascas de Erythrina velutina Willd. - Fabaceae (Leguminosae -Papilionoideae). Curitiba: Universidade Federal do Paraná, Ciências da Saúde, 103p. Dissertação Mestrado.

Virtuoso, S., Davet, A., Dias, J. F. G., Cunico, M. M., Miguel, M. D., Oliveira, A. B., \& Miguel, O. G. (2005). Estudo preliminar da atividade antibacteriana das cascas de Erythrina velutina Willd., Fabaceae (Leguminosae). Revista Brasileira Farmacognosia, 15, 137-142. https://doi.org/10.1590/S0102$695 \times 2005000200012$

Weidenhamer, J. D., Menelaou, M., Macias, F. A., Fischer, N. H., Richardson, D. R., \& Williamson, G. B. (1994). Allelopathic potential of menthofuran monoterpenes from Calamintha ashei. Journal Chemical Ecology, 20:2, 3345-359. https://doi.org/10.1007/BF02033731 